the Memorial Sloan-Kettering Cancer Center in New York used data from 12 cancer types to group tumours on the basis of genomic signatures rather than according to the organ in which the tumour originated. These signatures might one day be used to personalize cancer therapies.

Nature Genet. 45, 1127-1133; 1134-1140 (2013)

For a longer story on this research, see go.nature.com/nbqobm

\section{ASTRONOMY}

Fine weather on far-off planet

Skies are clear and blue on an extrasolar planet 14 times more massive than Earth.

Using the Large Binocular Telescope in Arizona, a team led by Valerio Nascimbeni at the University of Padua, Italy, studied ultraviolet and infrared light coming from the dwarf star GJ3470, 31 parsecs from Earth. By watching the star dim as a known planet passed in front of it, the astronomers could probe light scattered by the planet's atmosphere.

The data suggest that the planet has a blue, cloud-free sky, which could help to reveal the composition of its atmosphere. The data are also precise enough to suggest that ground-based telescopes can now be used to discover Earthsized planets around similar stars, rather than relying on space-based observatories. Astron. Astrophys. http://doi. org/n2b (2013)

\section{CLIMATE SCIENCES}

\section{How plants helped Earth to stay cool}

Plant growth spurred by rising levels of carbon dioxide pollution in the atmosphere has slowed the rate of global warming considerably.

Stephen Pacala of Princeton University in New Jersey and his colleagues used an Earth-system model to analyse historical emissions from industry and changes in land use, including deforestation and agricultural development. The team simulated the carbon cycle and climate from 1861 to 2005 with and without the fertilization effect of $\mathrm{CO}_{2}$ on vegetation.

Although the model did not incorporate certain factors, such as pre-1960 land use, the results suggest that if vegetation had not soaked up so much of the gas, levels of $\mathrm{CO}_{2}$ would have risen by an extra 85 parts per million - boosting temperatures by about $0.31^{\circ} \mathrm{C}$.

Proc. Natl Acad. Sci. USA http://doi.org/n2c (2013)

\section{ORGANIC ELECTRONICS}

\section{Sound shakes} semiconductors

Gently vibrating a solution of semiconductor molecules as they crystallize into a conductive film helps to reduce structural flaws. This yields higher-quality organic transistors that can be used in flexible, lightweight electronic devices.

A team led by Oana Jurchescu of Wake Forest University in Winston-Salem, North Carolina, used audio speakers operating at a lowfrequency of around 100 hertz to shake molecules as they formed a thin crystalline film (apparatus pictured). This boosted the film's semiconducting properties, making it almost as good a semiconductor as single crystals grown by diffusion

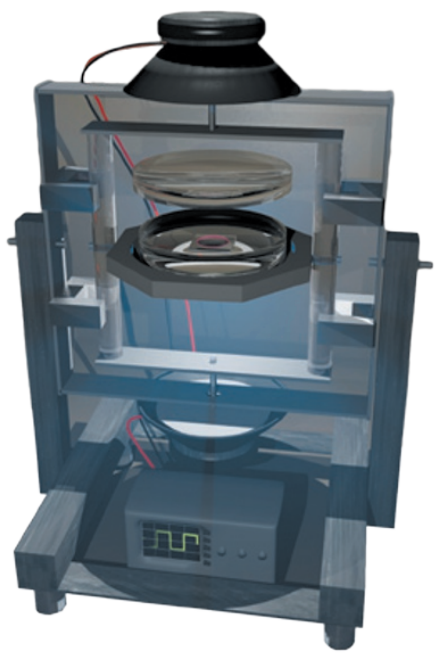

COMMUNITY CHOICE

The most viewed papers in science

\title{
Chimps ignore watching eyes
}

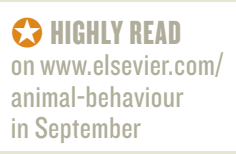

Unlike humans, chimpanzees do not alter their behaviour significantly when eyes are gazing down on them.

Daniel Nettle at Newcastle University, $\mathrm{UK}$, and his colleagues observed chimps (Pan troglodytes) consuming shelled peanuts in front of a large image of a chimp (pictured). Although chimps adjust their eating habits in the presence of dominant chimps and recognize such stylized black-and-white cartoons as faces, the animals in these experiments did not hesitate to take peanuts when 'watched' by the image. Humans are more charitable and honest under images of watching eyes than in their absence, and may be unique in their extreme sensitivity to faces, the authors say.

Anim. Behav. 86, 595-602 (2013)

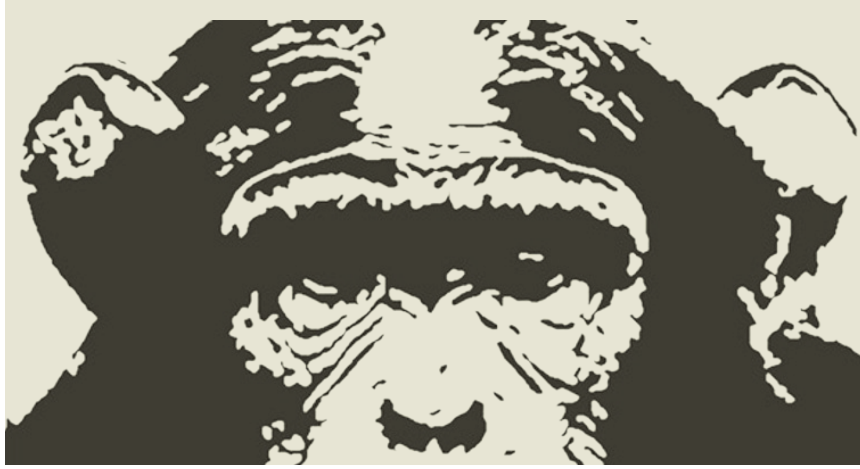

from molecular vapour - a method that, unlike shaking liquid solutions, does not lend itself to high-throughput manufacture at room temperature.

Other methods such as heating or including additives in the film also improve superconductivity, but vibration might be cheaper and more scalable, the researchers think.

Adv. Mater. http://

dx.doi.org/10.1002/ adma.201302838 (2013)

\section{Friction at the atomic scale}

The effect of atomic bonds on friction has been demonstrated, for the first time, at the scale of just a few atoms.

Variations in atomic surfaces are thought to modulate the force of friction in a way that depends on the direction in which objects are moved, but this has been difficult to show experimentally. Jay Weymouth of the University of Regensburg in Germany and his colleagues have now done so.

They passed the tip of a tungsten lateral-force microscope between regions of a silicon crystal surface, on which pairs of silicon atoms were oriented at right angles to each other. Oscillations of the tip varied depending on whether it was sliding along or across the direction of the paired atoms.

Phys. Rev. Lett. 111, 126103 (2013)

\section{$\rightarrow$ NATURE.COM}

For the latest research published by Naturevisit:

www.nature.com/latestresearch 